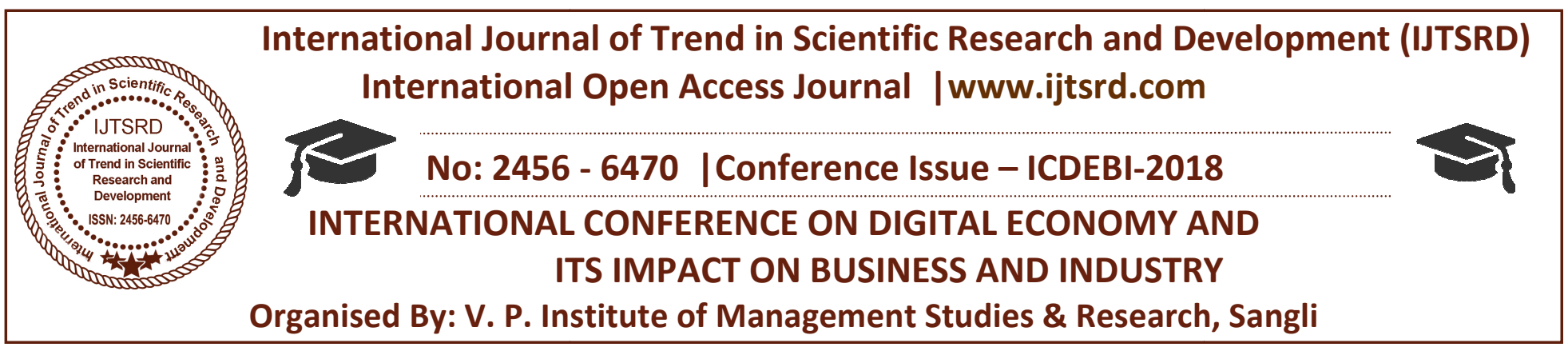

\title{
Using Data Analytics in Journalism Media Systems
}

\author{
Mr. Dinesh D. Kudache \\ Director, Techno well Web Solutions, India
}

\section{ABSTRACT}

From 2010-2018, the computational technology changes are made enormously. Technological gadgets like desktops, laptops are succeeded by mini laptops, tablets, smart phone, and watches.

The traditional journalism media systems said to be in dissolved states right now. In next upcoming decade the media communication of journalism will affect maximum number of changes. The top newspapers like New York Times, HuffingtonPost, Times magazine are also affected and willing to proceed for changes. The most of historic newspaper Medias are concentrating on digital platform from being destroyed in competitive world. The online subscriptions are given in suitable prices to end users / readers having special discounts, offers etc.

Using data analytics in offline media can lead to increase number of conversion to upcoming trend in gradual way.

\section{INTRODUCTION}

The journalism sector is changing from print media to digital. The top news agencies like Huffington post, New York Times, Time magazine are already suffering from readership loses. To stop readership and maintain the scope of journalism media in future, media should have to go digital platform. Using digital platform newspaper agencies or media division can analyze user interests, behavior, selection, choices, demands, problems, suggestions, feedback using special data analytics software's / tracking codes.

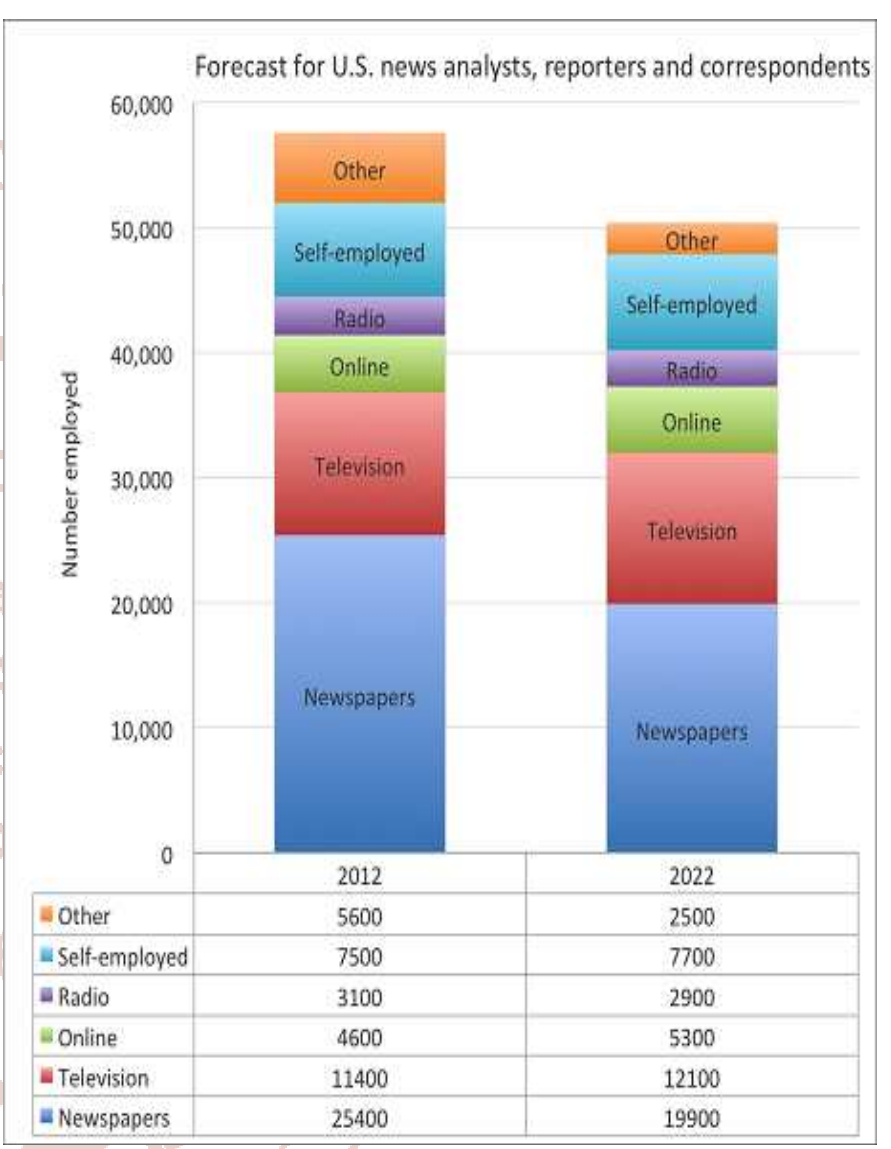

Fig.: A graph showing number of conversion of media manpower compare to 2012 Vs 2022

The special fact finding result of above chart is the rapid growth in technology. The social platforms like Facebook, Twitter, YouTube is available for each user using which anyone can exhibit his/her skills to public absolutely free of cost. It is growing online digital media. Also the main disadvantage of these platforms is authenticity of data / news being spread as viral. So offline media is said to be faithful in most of cases.

\section{Review of Application in Journalism}


i. Studying Expected Reader Category

Before starting any newspaper or magazine or maximizing reader base in certain area, research study is essential step. We have to work on user reading interest according to age, interest, gender, season, area, recommendations, trends and other social factors.

Data analytics tools like Alexa, Google Trends, Google Analytics, Twitter Trends, nearby social networking trends, online surveys will help you to work detail on content what people are searching. You can get clear idea about what user want, what they will like, how much reach will be achieved for certain article.

For example: If research study shows reader age in between $40-70$ years in certain city, $60 \%$ to that of overall population of city then editor should focus on events, activities, books, old fashioned articles, retirement plan, health related articles so on.

\section{ii. Studying Design Patterns, User Experience, Colors, Page Arrangements, Fonts.}

In today's competitive digital world or offline media, user experience for each product is said to be most important and essential aspect for growth. The following factors should be considered to achieve best goals of readers.

A. Studying design pattern layout of offline media like newspaper / magazine.

B. User flexible font sizes should be used as per importance. Proper bold, italics, alignment properties are secondary factors. Unicode based support and printing errors should be taken in mind.

C. Most of offline media printing works on a concept of CYMK color codes. We recommend to use two colors combination techniques. The colors should be decent, vibrant, catchy. The important news should be highlighted in an effective way.

D. Font size should be based on user age specifications. The news which is released for general public purpose should have at least +2 font size as compared to regular font size.

E. Page arrangements are also considerable fact in offline media segment. The pages should be ordered depending on severity of news heads, day and other holiday factor.
You can use Google material design (https://material.io) to study layout structure what user preferences to read.

\section{iii. Analysing Depth of No. of Reads / Article or Page}

In newspaper, it is best exercise to calculate user satisfaction regarding certain article or post. Your article should inspire user to give his opinion, feedback, comment, suggestion and recommendation if any. We can get such response in the form of Web API, QR codes, miss call alerts, reply numbers, sms, polling, surveys, direct contact number posting techniques. Such responded data should be collected and dumped in Tableau software to get depth of no. of readers / article or page.

\section{iv. Monitoring Each User Interest Activity under User Privacy Policy Compliance}

There are several interesting sections we can provide in newspaper or offline media. Like we can print jobs, jokes, poems, drawings, color filling jobs for child, joining dots, puzzles so on. This type of interest help user to interact with your concepts.

You can post company name as ad in puzzle question. This will induce brand management awareness about a product very easily.

This activity should be monitored / observed as per proper consent from user or giving him privacy policy statement in a printing or other way. You can inspire them giving attractive badges, points, and other techniques.

\section{v. Using QRcode / Patterns for Reference Videos, Feedback System}

News funnels should be designed such a way that user should react with news / article. We can give QRCode below article using which user can navigate to online feedback form / survey form. If certain article says about past details about a person they can simply provide video link embed in content area of news / article. The article looks like a running scenario.

\section{vi. Emergency News, Alerts, Notifications, Event System}

Suppose that there is an event going to exhibit in city Pune. User will read this event details. You can give access code to access it in his/her smart phone like event date, time, venue, place and other details. Tools like Google calendar, Apple notes, and Reminder systems will help to intimate you day before an actual event to be start. 
A crisis alerts can be sent to users those are registered with us on email or sms. We can push send notification to each user as per latest updates. Google crisis API is available to measure and work on data, causes, emergency helpline, tracks of historic data.

vii. Provision of Bookmark, Add To Reading List, Synchronization with Third Party Apps Like Apple, Android Cloud

Old fashioned newspapers are no responsive. The newspaper should talk with your opinions. The concept of bookmark is highlighted on the concept of user history about read. We can build specific web application or smartphone application either in android or iOS based platform.

When user reads certain story or article if he / she want to save this article for future reference purpose then such type of facility should be given for users. We can send bookmark request using AWS web links or API masks.

Apple Inc. gives Add to Reading List facility for Safari web browsers. We can send such reference links through API to cloud request. This will enhance the use of reference for news articles.

Synchronization is also one of the best useful features to sync in between offline media as well as online media / services.

\section{viii. Publishing Ads as Per Consumer Behavior}

Publishing ads in top leading newspapers is highly expensive. The giant e commerce companies like Amazon / Flip kart work on the concept of data mining and data analytics. The company focuses on top selling / trending products in certain area. Then application gives top list of most selling products. These products can be prepared or gathered together in the form of readymade design. The image quality can be maintained to proper aspect ratio without losing its proportion, colors or bit depth. The said design is sent to advertise / marketing department of newspapers according to region. Each design will reflect in design manner as per region changes. So, the final sales lead ratio will be achieved very easily because proper data history of users is viewed using special data software.

\section{ix. Product Placement in Trending News}

Suppose there is trending news about Elon Musk regarding Tesla Inc. Like. Tesla Inc. is going to introduce solar / electric cars. This news will attract the eyes of readers. Maximum lead ratio is achieved here. So brilliantly we can place smart ad campaign in between the content of such news like advertising dry cell batteries, dealer / franchise networks, new opportunities in electric industry so on.

\section{x. Pursuasion of Mind towards Using Online Versions of Media}

The future is centralized on digital media. In upcoming 10 years, the offline media will be vanished. Global warming is raising its position. Also people are now aware of global warming so they are willing to use solar based, environment friendly products in day to day use. Concept of paperless offline / social world will lead to expand positions.

So media should focus gathering or persuade the minds of offline reader base to navigate or move online. The attractive offers should be given to make them happy. Also production cost will be reduced due to online usage.

\section{CONCLUSIONS}

Using data analytics in journalism may help to reduce unskilled manpower in industry. We can automate news selections, procedures, real-time user activity so on. It will help to give the appropriate content to selected users interest using very less resources. Right now it is turning point for offline media / journalism industry.

The courses or graduation degree in the field of Mass and Journalism course should have latest syllabus of content management system, data analytics to use in media. Implementation of data analytic features in offline media can sustain further digital growth in future.

\section{REFERENCES}

1. John Pavlik (Vol 1,2000 - Issue 2): The impact of technology on journalism

2. Tableau: Tableau desktop and web authoring help for publishing content on a web

3. News initiative by Google: Data journalism, Google trends, Google public data explorer, Surveys, Google fusion tables, Google crisis map

4. SAP: Using SAP HANA enterprise cloud service $\mathrm{m}$ module in big data.

5. Statista : The Statistics Portal having statistics and studies from more than 22,000 sources

6. C Rajeshwari, DyutiBasu and NamitaMaurya : Comparative study of big data analytics tools : R and Tableau

7. IEE Explore digital library (Dec 2010): A suite of Google services for daily course evaluation 